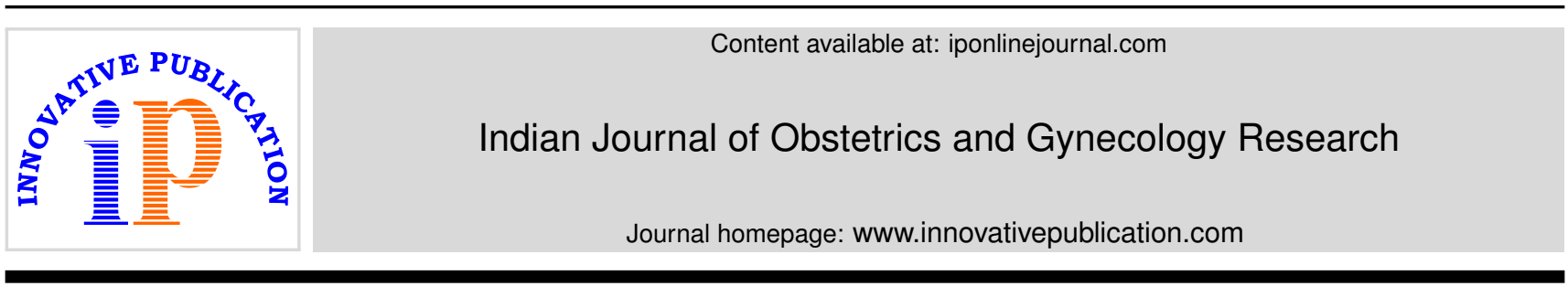

Original Research Article

\title{
Effectiveness of skin to skin contact between mother and baby at birth on maternal and neonatal outcomes among parturients
}

\author{
Reshma Punnoose ${ }^{1, *}$, Sulochana Kumar ${ }^{2}$, Jessy P S $\mathbf{S}^{3}$ \\ ${ }^{1}$ Dept. of Obstetrics and Gynecology, Government College of Nursing, Thiruvananthapuram, Kerala, India \\ ${ }^{2}$ Dept. of Obstetrics and Gynecology, Government College of Nursing, Kottayam, Kerala, India \\ ${ }^{3}$ Dept. of Child Health Nursing, Government College of Nursing, Kottayam, Kerala, India
}

\section{A R T I C L E I N F O}

Article history:

Received 17-12-2019

Accepted 03-04-2020

Available online 15-06-2020

\section{Keywords:}

Skin to skin contact between mother and baby at birth

Maternal outcomes

Neonatal outcomes

Parturients

\begin{abstract}
A B S T R A C T
Background: Third stage of labour is very crucial period in a women's life. Previously uneventful first and second stage can become abnormal within a minute with disastrous consequences. In the third stage, the mothers face many problems like haemorrhage, retained placenta and inversion of the uterus. Early skin to skin contact at birth along with the breastfeeding process is protective against the incidence and severity of PPH. This study was conducted to determine the effectiveness of skin to skin contact between mother and baby at birth on maternal and neonatal outcomes among parturients.

Materials and Methods: The objectives were to determine the effectiveness of skin to skin contact between mother and baby at birth on maternal outcomes among parturients and to determine the effectiveness of skin to skin contact between mother and baby at birth on neonatal outcomes among parturients. A quasi experimental research approach was used for the study. After obtaining permission from institutional ethical committee a total of 70 parturients admitted at labour room, Medical college hospital, Kottayam (35 each in control and experimental group) were selected for the study by purposive sampling technique. The data collection instruments were socio - personal and clinical data sheet, APGAR newborn scoring chart, observation checklist during third stage of labour, infant breastfeeding assessment tool (IBFAT), LATCH scale and modified maternal breastfeeding satisfaction evaluation scale (MBFES). Skin to skin contact between mother and baby at birth implemented in experimental group immediately after normal vaginal delivery for 30 minutes. Post-test for duration of third stage of labour, blood loss during third stage of labour, initiation of breast feeding, quality of first breast feeding and maternal satisfaction were performed within 80 minutes after normal vaginal delivery in control and experimental group. The data were tabulated and analyzed using descriptive and inferential statistics.

Results: The results of the study revealed that skin to skin contact between mother and baby at birth had statistically significant effect on maternal outcomes (duration of third stage of labour, blood loss during third stage of labour and maternal satisfaction) and neonatal outcomes (initiation of breastfeeding, quality of first breastfeeding and time of initiation of first breastfeeding $)(p<0.05)$.

Conclusions: The result revealed that skin to skin contact between mother and baby at birth had effect on reducing duration of third stage of labour and blood loss during third stage of labour, improving maternal satisfaction, initiation of breastfeeding, quality of first breastfeeding and time of initiation of first breastfeeding.
\end{abstract}

(C) 2020 Published by Innovative Publication. This is an open access article under the CC BY-NC license (https://creativecommons.org/licenses/by-nc/4.0/)

\footnotetext{
* Corresponding author.

E-mail address: reshmapunnoose26@gmail.com (R. Punnoose).
}

\section{Introduction}

Bringing a child into the world is a joyous moment. The goal of maternity care is a healthy pregnancy with a physically safe and emotionally satisfying outcome for mother, infant, and the family. 
Third stage of labour is very crucial period in a women's life. Previously uneventful first and second stage can become abnormal within a minute with disastrous consequences. In the third stage, the mothers face many problems like haemorrhage, retained placenta and inversion of the uterus. Globally, PPH was a leading cause of maternal mortality and the global prevalence of PPH was $6 \% .^{1}$ This may lead to increased mortality and morbidity rate. PPH is one of the major causes of maternal mortality around the world with a reported incidence of $2-11 \%$ and $8 \%$ in Asia. ${ }^{2}$ This can be prevented by breastfeeding especially early suckling. In women early suckling promotes bonding between mother and baby, involution of the uterus to prepregnant state, reduces the risk of primary post-partum haemorrhage and act as natural contraceptive.

Skin to skin contact (SSC) is an aspect of child rearing which might look simple and uncomplicated to some, but it is considered an art to experienced mothers. The skin to skin care and birth hormones positively influence the bond between mother and her baby at the moment of birth. Oxytocin, the hormone that causes the uterus to contract and stimulates mothering feelings after birth like touches, gazes at, and passion to breastfeeds her newborn. ${ }^{3}$

Early skin to skin contact during third stage of labour has a positive effect on its duration, completeness of placental separation, immediate uterine contraction, uterine position, the amount of blood loss and woman satisfaction and preference in future delivery. Moreover, SSC at birth along with the breastfeeding process may be protective against both the incidence and severity of PPH. Lower rates of PPH has the potential to decrease maternity morbidity. ${ }^{3}$ This study is an attempt to reveal the possibilities of skin to skin contact at birth and the advantages on mothers and newborns attending Labour Room in tertiary care hospitals.

\section{Materials and Methods}

\subsection{Research approach}

Quantitative quasi experimental research approach was adopted for this study.

\subsection{Research design}

In order to achieve the objectives of the study, posttest only control group design was used.

\subsection{Setting}

Labour room, Medical College Hospital, Kottayam.

\subsection{Population}

The population of the study represented all parturients.

\subsection{Sample and sample size}

Considering the study objectives and duration of the study, the sample consisted of 70 mothers (35 samples each in control and experimental group) undergoing normal vaginal delivery with episiotomy during the period of study.

\subsection{Sampling technique}

Non- probability purposive sampling was used to select mothers undergoing normal vaginal delivery.

\subsection{Inclusion criteria}

1. Mothers who are willing to participate in this study.

2. Mothers undergoing normal delivery between $37-40$ completed weeks of gestation.

3. Mothers with age of 18 years and above.

4. Mothers having singleton pregnancy with a live fetus.

5. Neonates with APGAR score more than 7.

\subsection{Exclusion criteria}

1. Mothers with psychiatric disorder

2. Mothers with severe pregnancy induced hypertension

3. Newborns of mothers with gestational diabetes mellitus

4. Mothers with placenta previa

5. Fetus with meconium stained amniotic fluid

\subsection{Description of the tool}

\subsubsection{Tool 1: Socio-personal clinical data sheet}

It was designed by the researcher based on reviewing the related scientific literature, opinion from experts and consisted of four parts.

Tool 1.1: Personal data of women such as age, occupation, education status and previous knowledge of mother on skin to skin contact at birth.

Tool 1.2: Obstetrical data of women such as parity, gestational age and duration of second stage of labour.

Tool 1.3: Newborn assessment data including APGAR score, weight of the baby and time of initiation of first breastfeeding after birth.

Tool 1.4: APGAR newborn scoring chart; In the present study APGAR scoring is taken as screening tool for intervention. Maximum score is 10 and minimum score is 0 .

\subsubsection{Tool 2: Observation checklist during third stage of labour}

It was designed by the researcher for assessment of duration of third stage of labour (in minutes), assessment of blood loss during third stage of labour (in millilitre) by weighing perineal towels pre and post use in delivery field (1gram = $1 \mathrm{ml})$. 


\subsubsection{Tool 3: Infant breastfeeding assessment tool (IBFAT)} It was adopted from Infant breastfeeding assessment tool by Matthews 1988, for assessing initiation of breastfeeding in order to get the baby feed, rooting, how long from placing baby on breast to latch or suck and sucking pattern. Maximum score is 12 and minimum score is 0 .

\subsubsection{Tool 4: LATCH scale}

It was adopted from LATCH assessment tool by Jenson, Wallace \& Kelsa (1994). which is a composite score of 010 is possible, depending upon the identified criteria met in each of the key areas of breastfeeding for assessing quality of first breastfeeding by the latch, audible swallowing, type of nipple, comfort and hold. Maximum score is 10 and minimum score is 0 .

\subsubsection{Tool 5: Modified maternal breastfeeding satisfaction evaluation scale (MBFES)}

This scale is using to assess maternal satisfaction with first breastfeeding. Modifications done on parameters with permission from Ellen Leaf, who developed the tool. It consists of 9 items scored according to 5 response categories. The response scale has a range of $1-5$ points. Total score is 45 , minimum score is 9 .

\subsection{Data collection procedure}

After obtains clearance from institutional ethical committee, 70 samples who fulfilled the inclusion criteria were included in the study. They were selected as first 35 parturients and next 35 parturients respectively. The purpose of the study was explained and consent was obtained from the participants prior to the data collection.

Routine care provided to the control group and skin to skin contact between mother and baby at birth had provided to the experimental group for 30 minutes after delivery. Post - test was performed by using socio personal clinical data sheet, APGAR newborn scoring chart, observation checklist during third stage of labour, infant breastfeeding assessment tool (IBFAT), LATCH scale and modified maternal breastfeeding satisfaction evaluation scale (MBFES) within 80 minutes after normal vaginal delivery.

\section{Results}

Descriptive statistics, frequency distribution and percentage were used to describe sample characteristics and Mann Whitney $U$ test was used to determine the effectiveness of skin to skin contact between mother and baby at birth on maternal and neonatal outcomes.

Table 1 describes the sample characteristics of both group. Majority of parturients in the control $(48.6 \%)$ and experimental group (54.3\%) were in the age group of 23 - 31 years. Majority $(60 \%)$ of the parturients in both groups were primipara. Only $8.6 \%$ in the experimental group were grand multipara. $42.9 \%$ of control group and $54.3 \%$ of experimental group were in the gestational age of 39 completed weeks. $57.1 \%$ in the control group and $42.9 \%$ in experimental group had the duration of second stage of labour in between $31-60$ minutes. Most of the newborns $(68.6 \%)$ in control group and $(74.3 \%)$ experimental group had birth weight of $2.5-3.5 \mathrm{~kg}$.

Table 2 depicts the effectiveness of skin to skin contact at birth on maternal outcomes among parturients. It shows that skin to skin contact between mother and baby at birth has effect on reducing duration of third stage of labour (U =405), reducing amount of blood loss during third stage of labour $(\mathrm{U}=264.5)$ and increasing maternal satisfaction $(\mathrm{U}=$ 11.5) among parturients in the experimental group ( $\mathrm{p}$ value $>0.05$ level).

Table 3 depicts the effectiveness of skin to skin contact at birth on neonatal outcomes among parturients. It shows that skin to skin contact between mother and baby at birth has effect on improving initiation of breastfeeding $(U=20)$ and improving quality of first breastfeeding $(\mathrm{U}=87)$ among parturients in the experimental group $(\mathrm{p}$ value $>0.05$ level).

\section{Discussion}

This study reveals that there is a significant difference in posttest scores of maternal outcomes after skin to skin contact between mother and baby at birth among parturients between control and experimental group. The component duration of third stage of labour were consistent with the findings of a similar randomized controlled clinical trial conducted in the delivery room at King Fahd Hospital of the University, Al Khobar, and Saudi Arabia and results demonstrated a significant positive effect of early SSC in shortening the duration of the placental delivery. ${ }^{4} \mathrm{~A}$ quasi experimental study was conducted at Government Ranees Hospital, Pudukkottai have similar result that early suckling was effective in reducing the duration of third stage of labour and blood loss. ${ }^{5} \mathrm{~A}$ randomized control trial observed that SSC led to higher maternal satisfaction rates than the study group. ${ }^{6}$

The present study observes that there is a significant difference in posttest scores of neonatal outcomes after skin to skin contact between mother and baby at birth among parturients between control and experimental group. Similar findings from a randomized control trial reveals that breastfeeding was initiated within 30 minutes of birth in $96 \%$ women in the study group compared to $41 \%$ in the control group. ${ }^{7}$ A quasi experimental study result shows that based on the LATCH scores, $48 \%$ of mothers who received SSC and $46 \%$ with routine care had successful breastfeeding. ${ }^{8}$ 
Table 1: Frequency distribution and percentage of parturients based on age of the mother, parity, gestational age in completed weeks, duration of second stage of labour in minutes and weight of the newborn $(\mathrm{N}=70)$

\begin{tabular}{|c|c|c|c|c|c|c|}
\hline \multirow[t]{2}{*}{ Sample characteristics } & \multicolumn{2}{|c|}{$\begin{array}{c}\text { Control group } \\
\qquad \mathbf{n}=\mathbf{3 5}\end{array}$} & \multicolumn{2}{|c|}{$\begin{array}{l}\text { Experimental group } \\
\qquad n=35\end{array}$} & \multirow[t]{2}{*}{ df } & \multirow[t]{2}{*}{$\chi^{2}$} \\
\hline & $\mathrm{f}$ & $\%$ & $\mathrm{f}$ & $\%$ & & \\
\hline \multicolumn{7}{|l|}{ Age of the mother } \\
\hline $17-22$ years & 12 & 34.2 & 10 & 28.6 & \multirow{4}{*}{3} & \multirow{4}{*}{0.63} \\
\hline 23 - 31 years & 17 & 48.6 & 19 & 54.3 & & \\
\hline 32 - 35 years & 3 & 8.6 & 4 & 11.4 & & \\
\hline $35-40$ years & 3 & 8.6 & 2 & 5.7 & & \\
\hline \multicolumn{7}{|l|}{ Parity } \\
\hline Primipara & 21 & 60 & 21 & 60 & \multirow{3}{*}{2} & \multirow{3}{*}{4.38} \\
\hline Multipara & 14 & 40 & 11 & 31.4 & & \\
\hline Grand multipara & 0 & 0 & 3 & 8.6 & & \\
\hline \multicolumn{7}{|c|}{ Gestational age (Completed weeks) } \\
\hline 38 & 12 & 34.2 & 10 & 28.6 & \multirow{3}{*}{2} & \multirow{3}{*}{0.9} \\
\hline 39 & 15 & 42.9 & 19 & 54.3 & & \\
\hline 40 & 8 & 22.9 & 6 & 17.1 & & \\
\hline \multicolumn{7}{|c|}{ Duration of 2nd stage of labour (In minutes) } \\
\hline $15-30$ & 2 & 5.8 & 0 & 0 & \multirow{3}{*}{2} & \multirow{3}{*}{4.19} \\
\hline $31-60$ & 20 & 57.1 & 15 & 42.9 & & \\
\hline $61-90$ & 13 & 37.1 & 20 & 57.1 & & \\
\hline \multicolumn{7}{|l|}{ Weight of the newborn } \\
\hline$<2.5 \mathrm{~kg}$ & 9 & 25.7 & 3 & 8.6 & \multirow{3}{*}{2} & \multirow{3}{*}{5.08} \\
\hline $2.5-3.5 \mathrm{~kg}$ & 24 & 68.6 & 26 & 74.3 & & \\
\hline$>3.5 \mathrm{~kg}$ & 2 & 5.7 & 6 & 17.1 & & \\
\hline
\end{tabular}

Table 2: Mean rank, sum of ranks and $U$ value of posttest score of maternal outcomes among parturients $(\mathrm{N}=70)$

\begin{tabular}{lccc}
\hline Group & Mean Rank & Sum of ranks & U value \\
Duration of third stage of labour & & & 1450.00 \\
Control $(n=35)$ & 41.43 & 1035.00 & 405 \\
Experimental $(\mathrm{n}=35)$ & 29.57 & & 1590.50 \\
Amount of blood loss during third stage of labour & & 894.50 & 264.5 \\
Control (n=35) & 45.44 & & \\
Experimental $(\mathrm{n}=35)$ & 25.56 & & 641.50 \\
Maternal satisfaction & 18.33 & 1843.50 & 11.5 \\
Control $(\mathrm{n}=35)$ & 52.67 & & \\
Experimental $(\mathrm{n}=35)$ & & & \\
\hline
\end{tabular}

Table 3: Mean rank, sum of ranks and U value of posttest score of neonatal outcomes among parturients $(\mathrm{N}=70)$

\begin{tabular}{lccc}
\hline Group & Mean Rank & Sum of ranks & U value \\
Initiation of breastfeeding & & & 650.00 \\
Control (n=35) & 18.57 & 1835.00 & 20 \\
Experimental $(\mathrm{n}=35)$ & 52.43 & & \\
Quality of first breastfeeding & & 717.00 & 87 \\
Control (n=35) & 20.49 & 1768.00 & \\
Experimental $(\mathrm{n}=35)$ & 50.51 & \\
\hline
\end{tabular}




\section{Conclusion}

The results of this quasi experimental trial depicted that skin to skin contact between mother and baby at birth had effect on reducing duration of third stage of labour and blood loss during third stage of labour, improving maternal satisfaction, initiation of breastfeeding, quality of first breastfeeding and time of initiation of first breastfeeding among parturients in experimental group. Further studies should be of sufficient power to assess maternal outcome like episiotomy pain perception and neonatal outcomes such as blood glucose level and thermoregulation. Similar study can be replicated among mothers underwent caesarean section.

\section{Acknowledgements}

We thank the almighty, our colleagues, family members and all other well-wishers for their guidance and support during the course of this study.

\section{Source of Funding}

Self.

\section{Conflict of Interest}

There are no conflicts of interest to be disclosed.

\section{Ethical Approval}

Institutional ethical committee clearance obtained (IEC No: $130 / 2018)$

\section{References}

1. Annual report 2013- 2014. Ministry of Health and Family welfare.
Government of India. Available from: https://mohtw.gov.In/annualreport-department-health-and-family-welfare--2016-17

2. Crenshaw J. Keep mother and baby together- It is best for mother, baby, and breastfeeding. J Perinat Educ. 2014;23(4):211-7.

3. Phillips R. The Sacred Hour: Uninterrupted Skin-to Skin Contact Immediately after birth. Newborn Infant Nurs Rev. 2013;13(2):67-72.

4. Al-Morbaty HY, Ashmauey AA, Aa AG. The effect of mother and newborn early skin-to-skin contact on the duration of separation and expulsion of the placenta. J Nurs Health Stud. 2017;2(2).

5. Sumithra S, Radha C, Mangai S. Effectiveness of Early Suckling on Third Stage Labour among Parturient Women at Government Ranees Hospital, Pudukkottai. Nurs J India. 2019;110(1):14-8.

6. Srivastava S, Gupta A, Bhatnagar A, Dutta S. Effect of very early skin to skin contact on success at breastfeeding and preventing early hypothermia in neonates. Indian J Public Health. 2014;58(1):22.

7. Parikh PM, Agrawal SP, Vyas RC, Shah SR, Joshi KP. Effect of early maternal newborn skin to skin contact in labour room on third stage of labour and success at breastfeeding. Int J Reprod, Contracept, Obstet Gynecol. 2018;7(12):5011.

8. Safari K, Saeed AA, Hasan SS, Moghaddam-Banaem L. The effect of mother and newborn early skin-to-skin contact on initiation of breastfeeding, newborn temperature and duration of third stage of labor. Int Breastfeed J. 2018;13(1):32.

\section{Author biography}

Reshma Punnoose Junior Lecturer

Sulochana Kumar Associate Professor

Jessy P S Assistant Professor

Cite this article: Punnoose R, Kumar S, Jessy P S . Effectiveness of skin to skin contact between mother and baby at birth on maternal and neonatal outcomes among parturients. Indian J Obstet Gynecol Res 2020;7(2):196-200. 